\title{
KỸ THUẬT CHUYỂN VỊ ĐộNG MẠCH ĐỐT SỐNG VÀO ĐộNG MẠCH CẢNH GỐC TRONG PHẪU THUẬT HYBRID - CHỈ ĐỊNH VÀ KỸ THUẬT
}

\begin{abstract}
Duong Ngọc Thắng*, Nguyễn Hưu Ước*, Nguyễn Tùng So*n*, Nguyễn Kim Dần*, Phạm Tiến Quân*, Lê Nhật Tiên*, Lê Đại Thạch*, Nguyễn Văn Đạt*, Nguyễn Xuân Đạt*
\end{abstract}

\section{TÓM TÁT}

Đặt vấn đề: Bắc cầu hoặc chuyển vị các động mạch xuất phát từ quai động mạch chủ (cảnh, dưới đòn) là kỹ thuật thường qui trong phẫu thuật Hybrid cho các tổn thương phức tạp của động mạch chủ ngực. Động mạch đốt sống là nhánh bên đầu tiên của động mạch dưới đòn trái, tuy nhỏ nhưng được khuyến cáo bảo tồn trong các phẫu thuật Hybrid. Trường hợp có bất thường giải phẫu - như động mạch đốt sống trái xuất phát thẳng từ quai động mạch chủ ..., thì nên điều trị theo cách nào. Mục tiêu của báo cáo là đề xuất chỉ định và kỹ thuật tái lập tuần hoàn động mạch đốt sống khi có bất thường giải phẫu (hoặc hẹp do xơ vữa) trong phẫu thuật Hybrid điều trị bệnh lý động mạch chủ ngực.

Phương pháp nghiên cứu: Nghiên cứu mô tả ba trường hợp lâm sàng bệnh lý - chấn thương vùng quai động mạch chủ có bất thường vị trí xuất phát động mạch đốt sống trái được điều trị bằng can thiệp nội mạch và tái lưu thông động mạch đốt sống vào động mạch cảnh chúng trái.

Kết quả: Không quan sát thấy biến chứng liên quan đến phẫu thuật và tái lập tuần hoàn động mạch đốt sống rất tốt trên phim chụp kiểm tra sau mổ.

Kết luận: Mặc dù chỉ định còn gây tranh cãi, tái thông động mạch đốt sống trái bất thường vào động mạch cảnh trái là kỹ thuật an toàn, đem lại lợi ích cho bệnh nhân, có thể thực hiện thường quy tại bệnh viện Hữu nghị Việt Đức.
Tù khóa: Hybrid, động mạch đốt sống, quai động mạch chủ, Việt Đức.

\section{DISPLACEMENT OF THE LEFT VERTEBRAL ARTERY WITH} ANATOMICAL ABNORMALITY TO LEFT CAROTID ARTERY IN THE THORACIC AORTIC HYBRID PROCEDURE INDICATION AND TECHNIQUE

\section{ABSTRACT}

Background: Bypass or displacement of the supra-aortic (carotid, subclavicular) arteries is a routine technique in hybrid surgery for complex lesions of the thoracic aorta. The vertebral artery is the first lateral branch of the left subclavicular artery, small but recommended for conservation in hybrid surgery. In the event of a anatomical abnormality - such as the left vertebral artery stemming directly from the cross of the aorta, how should it be treated. The objective of the report is to propose an indication and technique to re-establish vertebral artery circulation if having anatomic abnormality in hybrid surgery for thoracic aortic pathology.

Method: The study describes three clinical cases - aortic cross injury and pathology with an abnormality of the left vertebral origin location treated with endovascular intervention and revascularization of the vertebral artery into the left carotid artery.

\footnotetext{
Trung tâm Tim mạch và Lồng ngục, Bệnh viện Hũu nghi Việt Đức Nguoòi chịu trách nhiệm khoa học: PGS.TS. Nguyễn Hũu Ước Ngày nhận bài: 31/12/2020 - Ngày Cho Phép Đăng: 26/01/2021
} 
Results: No complications related to surgery and very good circulation of the vertebral artery were observed on postoperative screening CT-scan.

Conclusion: Although the indication is controversial, revascularization of the left vertebral artery into the left carotid artery is a safe and beneficial technique for patients, and can be routinely performed at Viet Duc University Hospital.

Keywords: Hybrid, vertebral artery, aortic cross, Viet Duc.

\section{I. ĐẶT VẤN ĐỀ}

Động mạch đốt sống (ĐMĐS) bên trái là nhánh bên đầu tiên của động mạch $(\mathrm{DM})$ dưới đòn trái, được khuyến cáo bảo tồn trong các kỹ thuật Hybrid vùng quai ĐM chủ do chức năng hỗ trợ cấp máu não ở người cao tuổi [1]. Kỹ thuật Hybrid thông thường là tái thông $\mathrm{ĐM}$ dưới đòn trái vào ĐM cảnh chung trái + thắt (bít) gốc ĐM dưới đòn. Như vậy ĐMĐS trái tiếp tục được cấp máu qua ĐM dưới đòn, không cần phải tái thông riêng cho ĐMĐS. Tuy nhiên, khi có bất thường giải phẫu - ĐMĐS trái xuất phát trực tiếp từ quai ĐM chủ, hoặc hẹp khít ĐMĐS có kích thước lớn do xơ vữa, thì cần phải tái thông riêng ĐMĐS vào $1 \mathrm{ĐM}$ nền cổ, mà thông thường là $Đ M$ cảnh chung trái. Đoạn gần của ĐMĐS là đoạn dễ phẫu tích và bộc lộ nhất, và cũng là đoạn hay xuất hiện thương tổn xơ vữa gây hẹp lòng mạch. Trên thế giới, phẫu thuật tái thông ĐMĐS đã được thực hiện từ nhiều năm trước với số lượng đáng kể, ví dụ tại Pháp - nghiên cứu của Koskas trong vòng 12 năm với số lượng bệnh nhân $(\mathrm{BN})$ là 610 [1]. Tuy nhiên ở Việt Nam, hiện chưa thấy có nghiên cứu hay tài liệu mô tả về kỹ thuật cũng như chỉ định phẫu thuật đối với ĐMĐS. Nhân ba trường hợp phẫu thuật chuyển vị ĐMĐS vào ĐM cảnh chung trái trên $\mathrm{BN}$ lóc $Đ \mathrm{M}$ chủ type $\mathrm{B}$, chúng tôi muốn đưa ra cái nhìn tổng quát về mặt kỹ thuật cũng như đóng góp thêm về chỉ định của phẫu thuật tái lập tuần hoàn ĐMĐS.

\section{TRƯỜNG HỢP LÂM SÀNG}

\section{Ca lâm sàng thứ nhất}

BN nam 70 tuổi, làm ruộng, sống cùng vợ và em trai, không rõ tiền sử tăng huyết áp, không đái tháo đường, hút thuốc lá và thuốc lào nhiều năm. BN nhập viện ngày 23/10/2019 vì lý do đau ngực trái - khởi phát cách 1 tuần, trong tình trạng tỉnh, không đau ngực, mạch 83 lần/phút, huyết áp (HA) 140/80mmHg. Các xét nghiệm lâm sàng, siêu âm tim, điện tâm đồ tại thời điểm nhập viện không thấy bất thường. Phim chụp cắt lớp vi tính đa dãy (MSCT) hệ mạch máu cho thấy: hình ảnh lóc ĐM chủ (ĐMC) từ sau chỗ xuất phát ĐM dưới đòn trái, ĐM thận trái xuất phát từ lòng giả, ĐM cảnh trong trái tắc hoàn toàn, ĐMĐS trái xuất phát từ quai ĐMC. $\mathrm{BN}$ được chẩn đoán lóc ĐMC type $\mathrm{B} / \mathrm{Tắc}$ hoàn toàn $\mathrm{ÐM}$ cảnh trong trái, ĐMĐS trái xuất phát từ quai ĐMC. Can thiệp bằng phẫu thuật Hybrid ngày 5/11/2019: Bắc cầu ĐM cảnh phải - trái và bắc cầu $Đ M$ cảnh trái - ĐM dưới đòn trái bằng mạch nhân tạo $\mathrm{PTFE}$ đường kính $7 \mathrm{~mm}$, tái lưu thông ĐMĐS trái bằng kỹ thuật chuyển vị vào $Đ M$ cảnh chung trái; đặt stentgraft Valiant $36 \times 32 \times 200 \mathrm{~mm}$ và $32 \times 32 \times 200 \mathrm{~mm}$ ĐMC từ sau chỗ chia ra thân ĐM cánh tay đầu phải đến trên chỗ chia ra ĐM thân tạng $3 \mathrm{~cm}$.

Kết quả: Chụp mạch khi tiến hành đặt stentgraft cho thấy các cầu nối lưu thông tốt, không có hiện tượng rò (endoleak) sau khi đặt stentgraft vào vị trí. Về mặt lâm sàng $\mathrm{BN}$ ổn định, rút ống nội khí quản ngay sau mổ, không có biểu hiện thiếu máu não sau mổ. Phim chụp MSCT ngày thứ 7 sau phẫu thuật cho thấy các cầu nối thông tốt, không có rò quanh stentgraft. $\mathrm{BN}$ được ra viện vào ngày thứ 11 sau mổ. 


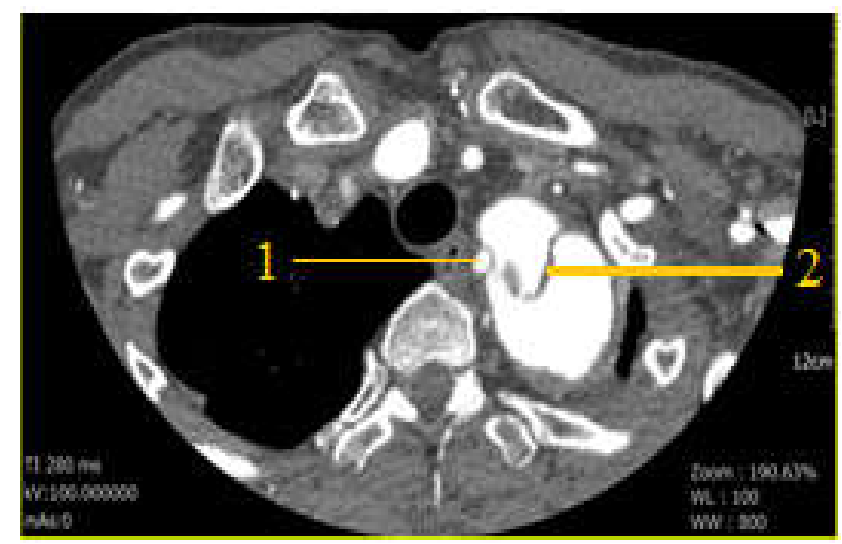

Hình 1. ĐMĐS trái xuất phát tù̀ quai ĐMC (1); Tổn thương lóc ĐMC (2) trên phim MSCT

\section{Ca lâm sàng thứ hai}

BN nam 51 tuổi, làm ruộng, tiền sử tăng huyết áp 1 năm điều trị không thường xuyên. $\mathrm{BN}$ được chuyển đến từ bệnh viện tỉnh Thái Nguyên vào ngày $21 / 12 / 2019$ do tình trạng đau ngực 5 ngày trước. Tại thời điểm vào viện, $\mathrm{BN}$ tỉnh, mạch 110 lần/phút, HA 170/100mmHg, không có dấu hiệu thần kinh khu trú, mạch ngoại vi rõ. Xét nghiệm khi vào viện thấy tình trạng hạ natri máu 126,3 mmol/1, các thăm dò chức năng khác không thấy bất thường. Kết quả MSCT hệ mạch máu cho thấy hình ảnh lóc tách ĐMC với lỗ rách lớn ngay sát chân ĐM dưới đòn trái lan lên quai ĐMC và lan xuống ĐM chậu gốc hai bên kèm theo nhiều ổ loét xuyên thành ĐMC xuống, ĐMĐS trái xuất phát từ quai ĐMC. $\mathrm{BN}$ được chẩn đoán lóc tách $Đ M$ chủ type $\mathrm{B} / \mathrm{b}$ ất thường vị trí xuất phát ĐMĐS trái/ tăng HA. Can thiệp bằng phẫu thuật Hybrid ngày 02/01/2020: Bắc cầu ĐM cảnh phải - trái bằng mạch nhân tạo $\mathrm{PTFE}$ đường kính $7 \mathrm{~mm}$, tái lưu thông ĐMĐS trái và ĐM dưới đòn trái bằng kỹ thuật chuyển vị vào $\mathrm{ĐM}$ cảnh chung trái, đặt stentgraft Relay plus $36 \times 32 \times 250 \mathrm{~mm}$ ĐMC ngực từ sau chỗ chia ra thân ĐM cánh tay đầu phải đến trên chỗ chia ra ĐM thân tạng $3 \mathrm{~cm}$.
Kết quả: Chụp MSCT kiểm tra ngày thứ 5 sau mổ cho thấy các cầu nối thông tốt, không có hiện tượng rò đối với stentgraft. $\mathrm{BN}$ được ra viện ngày thứ 7 sau mổ.

\section{Ca lâm sàng thư ba}

BN nam 42 tuổi, tiền sử khỏe mạnh, tai nạn ngã cao $2 \mathrm{~m}$ ngày 02/03/2020, đã nhập viện Bãi Cháy - Quảng Ninh với chẩn đoán đa chấn thương: chấn thương ngực kín xử trí dẫn lưu màng phổi hai bên, chấn thương cột sống vỡ T12, L1, L2, chấn thương bụng kín tụ máu khoang sau phúc mạc. Ngày 12/03/2020, BN đau ngực tăng, khó thở nhiều được đặt ống nội khí quản, chụp MSCT lồng ngực phát hiện tổn thương vỡ eo ĐMC, ĐMĐS trái xuất phát từ quai ĐMC. BN được chuyển đến bệnh viện Hữu nghị Việt Đức. Can thiệp phẫu thuật Hybrid ngày 13/03/2020: phẫu thuật chuyển vị ĐM dưới đòn trái và ĐMĐS trái vào ĐM cảnh gốc trái, đặt stent graft ĐMC ngực Valiant 28x28x150mm vào vị trí sau ĐM cảnh gốc trái.

Kết quả: Chụp kiểm tra trong mổ cho thấy các mạch máu thông tốt, không có rò từ stentgraft. BN được chuyển khoa phẫu thuật cột sống điều trị tiếp ngày thứ $5 \mathrm{sau}$ phẫu thuật. 

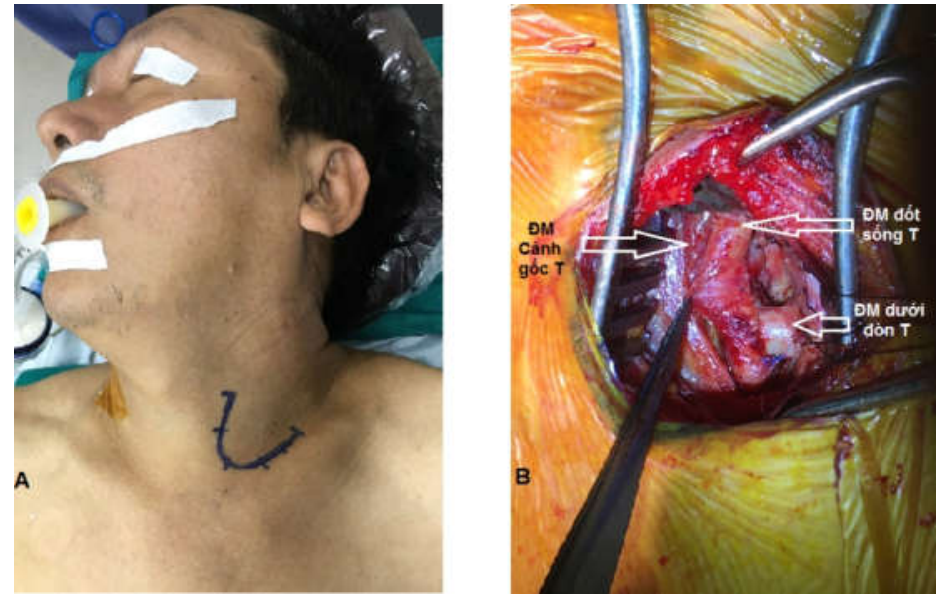

Hình 2. Tu thế $B N$ và vị trí rạch da $(A)$ - ĐM dưới đòn và ĐMĐS được nối với ĐM cảnh gốc

Kỹ thuật chuyển vị ĐMĐS vào $\boxplus M$ cảnh chung trái:

$\mathrm{BN}$ nằm ngửa, kê gối dưới vai, cổ ngửa tối đa và cố định đầu quay phải tối đa (Hình $2 \mathrm{~A})$. Đường rạch song song bờ trước cơ ức đòn chũm trái, bộc lộ ĐM cảnh chung trái đoạn trước khi chia ra $Đ M$ cảnh trong và cảnh ngoài. Để bộc lộ ĐM đốt sống đoạn V1, vén ĐM cảnh chung và thần kinh $\mathrm{X}$ vào trong, tĩnh mạch cảnh trong ra ngoài, mở cân cổ sâu, thắt và cắt rời tĩnh mạch đốt sống bắt chéo trước ĐMĐS. Phẫu tích ĐM đốt sống trên đoạn dài khoảng $4 \mathrm{~cm}$ từ sát chỗ ĐM chui vào lỗ mỏm ngang đốt sống cổ C6 về phía nguyên ủy. Tiêm heparin tĩnh mạch liều 50UI/kg cân nặng, kẹp bên ĐM cảnh chung trái, mở mạch khoảng $1 \mathrm{~cm}$, kẹp và cắt rời đầu gần $Đ M$ đốt sống trái, đóng đầu dưới, làm miệng nối giữa ĐM đốt sống trái và ĐM cảnh chung trái kiểu tận bên bằng chỉ prolene 6.0 mũi vắt (Hình $2 \mathrm{~B}$ ). Thời gian kẹp ĐM cảnh gốc trái và ĐMĐS trái để làm miệng nối cho 3 ca lâm sàng của chúng tôi lần lượt là 11,12 và 11 phút.

\section{BÀN LUẬN}

Giải phẫu ĐMĐS (Hình 3): ĐMĐS có đường kính khoảng 3-5mm, được phân chia thành 4 đoạn: Đoạn V1 - ĐM đốt sống tách ra từ ĐM dưới đòn đi lên trên rồi chui vào lỗ đốt sống của đốt sống cổ C6; đoạn V2 - tính từ vị trí đi vào lỗ đốt sống C6 đến lỗ đốt sống C2; đoạn V3 - đoạn dưới xương chẩm tính từ vị trí đi ra khỏi lỗ đốt sống C2 đến vị trí ĐM xuyên qua màng cứng ở lỗ chẩm; đoạn V4 - đoạn trong sọ từ lỗ chẩm đến chỗ hợp lưu với ĐM đốt sống bên đối diện.

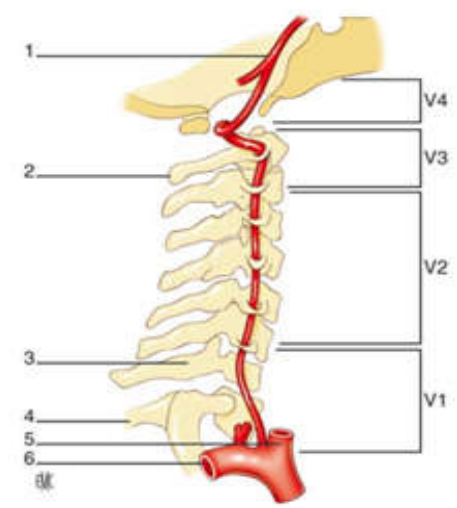

Hình 3. Giải phẫu $Đ M Đ S ~[8]$ 
Bất thường nguyên ủy ĐMĐS trái là hình thái bất thường quai ĐMC ít gặp, chiếm khoảng $2,4 \%$ đến $5,8 \%$ dân số [2]. ĐMC được hình thành từ mầm ĐMC bụng và mầm ĐMC lưng ở tuần thứ 3 , từ đó chia ra 6 nhánh quai ĐMC [3]. Quá trình quay của rễ ĐMC lưng phải và ống động mạch phải hình thành quai ĐMC bình thường. Tất cả những sai lệch trong quá trình này sẽ gây ra các biến đổi giải phẫu của quai ĐMC. Hay gặp nhất là quai ĐMC kiểu "bovine" với thân chung ĐM cảnh chiếm $10-22 \%$, hẹp eo ĐMC chiếm $5-7 \%$ và ĐMĐS trái xuất phát từ quai chiếm 2-6\% [4]. Mặc dù bất thường giải phẫu của ĐMĐS trái không gây ra bất kỳ triệu chứng lâm sàng nào, nhưng biến đổi này có thể liên quan đến nguy cơ lóc ĐMC. Tapia và cộng sự [5] quan sát thấy liên quan có ý nghĩa thống kê giữa bất thường vị trí xuất phát của ĐMĐS trái với tổn thương lóc ĐMC type $\mathrm{B}$. Nghiên cứu trên chỉ ra rằng hình thái của quai ĐMC quyết định vị trí lỗ vào của thương tổn lóc ĐMC. Tuy nhiên cần có thêm các nghiên cứu về huyết động để khẳng định kết quả trên.

Việc nắm vững các biến đổi giải phẫu của mạch máu xuất phát từ quai ĐMC rất quan trọng trong các trường hợp điều trị bệnh lý ĐMC. Có khoảng $40 \%$ các trường hợp đặt stentgraft ĐMC cần che lỗ xuất phát của ĐM dưới đòn trái [6]. Tái lập tuần hoàn ĐMĐS khi đặt stentgraft ĐMC ngực cho phép duy trì tưới máu cho vùng não sau. Đối với các trường hợp ĐMĐS xuất phát từ quai ĐMC, Mitchell và cộng sự [7] sử dụng phân loại cải tiến cho vị trí bắt đầu của stentgraft, trong đó vùng 2 được chia thành 2 vùng: $2 \mathrm{a}$ (stentgraft đặt ở vị trí phía xa lỗ vào ĐM cảnh trái qua hết phía gần ĐMĐS trái); và $2 \mathrm{~b}$ (stentgraft che vị trí phía xa lỗ vào ĐMĐS trái qua hết phía gần ĐM dưới đòn trái). Các tác giả Trung Quốc [8] khuyến cáo thực hiện tái thông ĐMĐS trái khi stentgraft ở vùng 1 và vùng $2 \mathrm{a}$ nếu ĐMĐS trái ưu thế hoặc không ưu thế nhưng tuần hoàn đa giác Willis không hoàn thiện. Theo nghiên cứu của
Rizvi và cộng sự, trên $\mathrm{BN}$ được đặt stentgraft ĐMC ngực và che lỗ vào ĐM dưới đòn trái, có $6 \%$ thiếu máu tay trái, $4 \%$ thiếu máu tủy, $2 \%$ thiếu máu não vùng sống nền [9]. Hướng dẫn của Hội phẫu thuật mạch máu thế giới (SVS) cũng chỉ khuyến cáo tái lưu thông ĐMĐS trái và ĐM dưới đòn trái trong một số trường hợp nhất định [10]. Tuy nhiên tại Trung tâm Tim mạch và Lồng ngực, bệnh viện Hữu nghị Việt Đức, trong những năm gần đây đã thực hiện tái thông ĐMĐS và/hoặc $Đ M$ dưới đòn trái cho tất cả các $\mathrm{BN}$ được điều trị bằng kỹ thuật đặt stentgraft ĐMC ngực có che lỗ vào $Đ M$ dưới đòn trái. Theo quan điểm của chúng tôi, việc tái lập tuần hoàn ĐMĐS trái và/hoặc ĐM dưới đòn trái đem lại các lợi ích sau: thư nhất, duy trì tưới máu cho vùng não sau và tủy sống nhất là trong trường hợp có kèm theo thiểu sản ĐMĐS bên phải hoặc đa giác mạch Willis được hình thành chủ yếu từ ĐMĐS trái hoặc stentgraft che lấp ĐM tủy sống (ĐM Adamkiewicz); thư hai, duy trì tình trạng tưới máu cho tay trái rất quan trọng với các $\mathrm{BN}$ thuận tay trái, những $\mathrm{BN}$ có nghề nghiệp đặc biệt cần sử dụng cả hai tay như vận động viên, nhạc công...; thư $b a$, với những $\mathrm{BN}$ trẻ tuổi, thời gian sống thêm dài, việc tái lập tuần hoàn $\mathrm{ĐM}$ dưới đòn giúp duy trì lưu lượng tuần hoàn của $\mathrm{ĐM}$ ngực trong để sử dụng trong phẫu thuật bắc cầu chủ vành hoặc tạo thông động tĩnh mạch tay trái nếu BN có suy thận trong tương lai; thứ tur, trong khi thực hiện phẫu thuật, chúng tôi tiến hành thắt gốc của ĐMĐS và ĐM dưới đòn trái, làm giảm nguy cơ rò (endoleak) type 2 sau đặt stentgraft, không cần tiến hành thủ thuật nút ĐMĐS trái hoặc ĐM dưới đòn trái.

Về mặt kĩ thuật tái lập tuần hoàn ĐMĐS, có thể sử dụng kĩ thuật chuyển vị ĐMĐS trực tiếp vào $Đ \mathrm{M}$ cảnh gốc trái hoặc tạo cầu nối giữa $\mathrm{ĐM}$ đốt sống trái và $\mathrm{ĐM}$ dưới đòn trái bằng tĩnh mạch hiển hoặc đoạn mạch nhân tạo. Theo Blumberg và cộng sự [11], các phẫu thuật tái lập tuần hoàn 
ở đoạn đầu của ĐM đốt sống có tỉ lệ tai biến mạch não và tử vong sau mổ chỉ khoảng $0,9 \%$ trong khi đó các phẫu thuật tái lập tuần hoàn ở đoạn xa có tỉ lệ tai biến mạch não và tử vong cao gấp 3 lần. Do số lượng $\mathrm{BN}$ trong nghiên cứu của chúng tôi còn ít, không quan sát thấy các tai biến liên quan đến phẫu thuật như: tụ dịch, rò bạch huyết, tắc cầu nối, chảy máu, giả phồng miệng nối mạch máu, tai biến mạch não, tử vong. Nhưng qua kết quả của 3 ca lâm sàng cho thấy phẫu thuật tái lập tuần hoàn ĐMĐS là phẫu thuật khá an toàn với thời gian phẫu thuật ngắn, vết mổ nhỏ, thời gian thiếu máu não ngắn, thời gian kẹp ĐM cảnh gốc trái và ĐMĐS trái để làm miệng nối đều dưới 15 phút - trong giới hạn cho phép về ngoại khoa.

\section{KẾT LUẬN}

Phẫu thuật tái lập tuần hoàn ĐMĐS trong điều trị bệnh lý - chấn thương tại vùng quai ĐMC và ĐMC xuống bằng can thiệp nội mạch vẫn còn là vấn đề gây tranh cãi. Tuy nhiên tại Trung tâm Tim mạch và Lồng ngực, bệnh viện Hữu nghị Việt Đức, chúng tôi tiến hành một cách thường quy do những lợi ích của phẫu thuật, đồng thời nó cũng không gây thêm biến chứng hay ảnh hưởng đến kết quả can thiệp nội mạch điều trị bệnh lý ĐMC. Trong tương lai, chúng tôi dự kiến sẽ tiếp tục tiến hành các phẫu thuật này và nghiên cứu kết quả lâu dài của phẫu thuật.

\section{TÀI LIỆU THAM KHẢO}

1. Koskas et al. (1995). Direct transposition of the distal cervical vertebral artery into the internal carotid artery. Annals of Vascular Surgery, 9(6), 515-524.

2. Lemke AJ, Benndorf G, Liebig $\mathrm{T}$ et al. (1999). Anomalous origin of the right vertebral artery: review of the literature and case report of right vertebral artery origin distal to the left subclavian artery. AJNR Am J Neuroradiol, 20,1318-1321.

3. Kau T, Sinzig M, Gasser J et al. (2007).
Aortic development and anomalies. Semin Intervent Radiol, 24,141-152.

4. Layton K, Kallmes DF, Cloft HJ et al. (2006). Bovine aortic arch variant in humans: clarification of a common misnomer. AJNR Am J Neuroradiol, 27,1541-1542.

5. Tapia G.P., Zhu X., Xu J. et al. (2015). Incidence of branching patterns variations of the arch in aortic dissection in Chinese patients. Medicine (Baltimore), 94,795.

6. Feezor RJ, Martin TD, Hess PJ et al. (2007). Risk factors for perioperative stroke during thoracic endovascular aortic repairs (TEVAR). J Endovasc Ther, 14, 568-573.

7. Mitchell R.S., Ishimaru S., Ehrlich M.P. et al. (2002). First International Summit on Thoracic aortic endografting: roundtable on thoracic aortic dissection as an indication for endografting. J Endovasc Ther, 9,98-105.

8. Huanyu Ding, Yi Zhu, Huiyong Wang et al. (2019). Management of type B aortic dissection with an isolated left vertebral artery. Journal of vascular surgery, 70(4), 1065-1071.

9. Rizvi AZ, Murad MH, Fairman RM et al. (2009). The effect of left subclavian artery coverage on morbidity and mortality in patients undergoing endovascular thoracic aortic interventions: a systematic review and metaanalysis. J Vasc Surg, 50,1159-1169.

10. Matsumura JS, Lee WA, Mitchell RS et al. (2009). The Society for Vascular Surgery Practice Guidelines: management of the left subclavian artery with thoracic endovascular aortic repair. J Vasc Surg, 50,1155-1158.

11. Sheila N. Blumberg, Mark A. Adelman, Thomas S. Maldonado (2017). Aberrant left vertebral artery transposition and concomitant carotidsubclavian bypass for treatment of acute intramural hematoma with thoracic endovascular aortic repair. Journal of vascular surgery, 65(3), 860-864. 